\title{
The study on value co-creation behaviour of shared bicycle users
}

\author{
Yashun Zhang ${ }^{1, \mathrm{a}}$ \\ ${ }^{1}$ School of Management, Shanghai University, China
}

\begin{abstract}
In the past few years, shared bicycles without piles developed so fast, they also experienced problems such as unregulated bicycle parking and unrepaired damaged bicycles. This article's study about users' consciously participating in the reporting damaged or illegal vehicles, encourages shared bicycle users' value co-creation behaviours, and strengthens the interaction between companies and users. This paper uses the combination of qualitative and quantitative methods to analyse the reliability and validity of the collected questionnaires, and uses the structural equation model to test the relevant hypotheses. It draws the conclusion that sense of responsibility, sense of accomplishment, expected revenue, peer acceptance, and self-efficacy have positive impacts on the value co-creation behaviour of shared bicycle users. The value creation behaviour of users has a positive impact on process satisfaction and result satisfaction.
\end{abstract}

\section{Introduction}

The development of shared bicycles has been more than 50 years. With the continuous improvement of technology and models, shared bicycles have brought great conveniences to people's daily life. Nowadays, the emergence of pile-free shared bicycles is more convenient for people's daily life because people don't have to access and return shared bikes at a fixed location.

But while it brings convenience to people's daily lives, it also raises a series of problems. For example, the irregular parking of bicycles affects the cleanliness of the entire city, and it also poses a certain obstacle to the normal driving of motor vehicles. At the same time, users' lives will be greatly threatened during the use of damaged vehicles that have not been repaired in time. Although the LBS system is installed on the vehicle, due to the large user group and the complexity of the actual situation, it is difficult for the shared bicycle company to monitor the user's usage behaviour and the damage situation of the vehicle through the positioning service.

Some domestic non-pile shared bicycle companies have guided users to participate in value creation activities by linking users' usage behaviours with credit mechanisms. However, there is not much literature research on why users are willing to invest time and energy into such value co-creation behaviours and the results of value co-creation behaviour. Therefore, through the online and offline questionnaire survey, this paper analyses the factors that affect the user's participation in value co-creation behaviour, and the results of value co-creation behaviour through qualitative and quantitative way. The analysis results play an active guiding role for other sharing companies to encourage users to engage in similar value co-creation behaviours.
At the same time, people's increasingly active and conscious behaviour will also bring positive development to the society as a whole and the improvement of morality.

\section{The literature Review}

\subsection{Shared Bicycles}

Since the launch of the "White Bike" campaign in Amsterdam in 1965, the development of shared bicycles has gone through four generations. ${ }^{1}$

As technology continues to improve, the safety, durability and convenience of shared bicycles continue to improve throughout this process.

China's shared bicycles were developed from the third generation. According to the establishment of the urban public bicycle system, that is, by means of the Internet and the information system, the geographical location of the user's riding vehicles can be tracked by positioning, while the setting of the fixed piles also greatly reduced the occurrence of bicycle theft.

The emergence of the fourth generation of pile-free shared bicycles allows people to access and return bicycles in the regulated area anytime and anywhere, providing convenience for people's daily travel, and also changing the way many people travel.

\subsection{Value Co-creation Behaviour}

Prahalad and Ramaswamy first proposed the concept of value creation in 2004 . They believe that producers and consumers jointly create the value of a product or service, rather than the producer alone. ${ }^{2}$ Vargo and Lusch jointly 
proposed service-led logic, in which value is created by companies and consumers by integrating resources. Since then, a large number of scholars have begun to study the value creation behaviour of users in the field of production and consumption.

Hoyer constructed a conceptual framework for the customer engagement value co-creation process, and the motivations for participating customers in value cocreation activities were classified as financial, social, technical and psychological factors. ${ }^{3}$ Louise and Roman pointed out in the article that the motivational factors that influence customers' participation in the online community's value co-creation activities include fun, monetary rewards, corporate and others recognition, reciprocity, and sharing experiences to enhance professional reputation. Fiiller divides the motivation for participation in value creation into four different types: reward-oriented, demand-driven, curiosity-driven, and intrinsic interest. ${ }^{4}$ Wang Xinxin and Xue Haibo pointed out in the research that the motivation of consumers involved in the brand community includes social motivation, information motivation, ability achievement motivation, economic interest motivation and leisure entertainment motivation, among which social motivation plays the most important position. ${ }^{5}$

\subsection{Value Co-creation Behaviour of Shared bicycle users}

For the shared bicycle users, during the riding process, it is found that the reporting of vehicle damage and illegal vehicle users through the APP or the customer service are embodiment of the value-creating activities of participating in the shared bicycle company. The qualitative and quantitative analysis of the motivational factors and results of the participation of the shared bicycle users in the value-creation activities can help the shared bicycle companies to develop a targeted incentive mechanism, encourage users to actively participate in the value creation activities, and enhance the users' satisfaction and regulate social order.

\subsection{Value Co-creation Result}

Users will have a comparative evaluation of the process and results after participating in the value creation. This article is expressed by user satisfaction. An in-depth study of user satisfaction stems from the gap theory in social psychology. This theory states that customers compare actual experience with pre-consumer standards after consumption, and the resulting gap determines customer satisfaction. In the article, scholar Oliver proposed that user satisfaction is closely related to consumers' product acquisition and consumption experience. It is a kind of transient and emotional evaluation with surprise or disappointment. Peng Yanjun pointed out that participation in value creation can provide a way for consumers to pursue satisfaction, sense of accomplishment, including participation in the process and results. ${ }^{6}$

\section{Research Models and Assumptions}

\subsection{Sense of Responsibility}

The sense of responsibility refers to the spirit of a person's initiative to exert positive and beneficial effects on himself, the natural world and human society, including the state, society, the collective, the family and others. It is a kind of conscious subject consciousness of human beings. Muniz's research found that the customer's sense of ethical responsibility reflects its sense of responsibility to the entire society and individual members of society. ${ }^{7}$

When the user sees the damaged or illegal vehicle, the inner sense of responsibility prompts them to choose to report, because it is convenient for the use of others, and this behaviour also plays a positive role in the order regulation of the urban road and the improvement of the social atmosphere. Therefore this paper proposes the hypothesis:

H1 Sense of responsibility has a positive impact on the value co-creation behaviour of shared bicycle users

\subsection{Sense of Accomplishment}

The sense of accomplishment refers to a psychological feeling that balances desire and reality. Swartz believes that the reason why customers want to participate actively and want to get pleasure and satisfaction through participation is one of the important motivation factors. ${ }^{8}$ Peng Yanjun pointed out in the literature that the intrinsic motivation can make consumers feel a sense of accomplishment, and people are also very interested in the activity itself. In the value-creation behaviour of shared bicycles, they choose to report damaged or illegal vehicles because they will have a sense of satisfaction after the damaged vehicles reported by them are repaired and put into normal use. The sense of pleasure is also motivating them to engage in similar value creation activities. Therefore this paper proposes the hypothesis:

$\mathrm{H} 2$ Sense of accomplishment has a positive impact on the value co-creation behaviour of shared bicycle users.

\subsection{Company Identity}

Scott and Lane, the first to extend organizationally recognized relationships from employees to businesses (including businesses and suppliers, consumers, etc.), believe that organizational identity is central, continuous, and unique characteristics of the organization shared between managers and stakeholders. Dukerich pointed out in the article that the higher the recognition of the organization members to the organization, the stronger their participation.

In the value-creation activity of shared bicycles users, their recognition towards shared bicycle company's values and products will encourage them to participate in the activity. Because they feel that their participation has a positive impact on the company's better product improvement and better service in the future, this paper proposes the following assumptions: 
H3 Company identity has a positive impact on the value co-creation behaviour of shared bicycle users.

\subsection{Expected Revenue}

Expected revenue was first proposed in the theory of expectation, and Bhattacherjee believes that the first step in commodity trading is that the user forms an expectation before a transaction for a particular product or service. Moreland believes that individuals will make personal contributions to the group as long as they believe that their efforts will directly or indirectly bring some benefits. ${ }^{9}$

In the use of shared bicycles, users have an expectation before they can report the damage situation of the vehicle, that is, they can get a higher credit score, or get some other extra rewards. This expectation promotes the users' co-creation behaviour. The assumption is as follow:

H4 Expected revenue has a positive impact on the value co-creation behaviour of shared bicycle users.

\subsection{Peer Acceptance}

Edvardsson's article suggests that social interaction has an important impact on value creation, and people often compare it with others. ${ }^{10} \mathrm{In}$ addition, the same user's perception is also considered to be a very important motivation to promoting users' value creation activities.

When choosing to report a damaged or illegal vehicle, many users have the idea that their behaviour can be recognized by others and trusted by others, so this paper proposes:

H5 Peer acceptance has a positive impact on the value co-creation behaviour of shared bicycle users.

\subsection{Self-efficacy}

Bandura first proposed self-efficacy in 1977, referring to the degree of conviction that an individual can successfully accomplish a certain behaviour to achieve the desired goal. It mainly emphasizes the subjective estimation and judgment of the individual's ability.

In fact, it is important to set effective rules for the successful operation of a pile-free shared bicycle. If the user can clearly understand how to report the bicycle damage and how to report the illegal user, it will bring the artificial monitoring cost reduction to the enterprise, and the timely processing of the user feedback can also improve the users' satisfaction to the corporate brand. Based on this, the paper makes the following assumptions:

H6 self-efficacy has a positive impact on the value co-creation behaviour of shared bicycle users.

\subsection{Customer Satisfaction}

The existing research is more concerned with the process of public participation in value co-creation behaviour, but there is less research to pay attention to the results produced. Avnet's research shows that in addition to the results, the course of action will have an impact on people's emotional experience. ${ }^{11}$ In the article, James pointed out that when customers get more positive service results through their own participation behaviour, they will reach a more satisfactory level. After users participation in the value-creation activities of shared bicycles, their satisfaction with the feedback results will further influence the participation of the next value creation activity, that is, if the feedback can be processed in time, and the user gets a certain reward, these will improve customers' satisfaction towards the results of value co-creation activities, which will stimulate the user's next participation process. The satisfaction of the process of this paper refers to the satisfaction evaluation of whether the operation is simple and time-saving in reporting the value-creating activities such as damaged vehicles, and whether the whole experience is smooth. The satisfaction of the results refers to after the users' participation in the shared bicycle value co-creation activity, whether the feedback problem is dealt with in time and whether the income obtained meets the expected satisfaction assessment. Based on this paper, the research hypothesis is proposed:

H7 The value co-creation behaviour of shared bicycle users has a positive impact on process satisfaction.

H8 The value co-creation behaviour of shared bicycle users has a positive impact on the result satisfaction.

Based on the above theoretical model and research hypothesis, the conceptual model proposed in this paper is shown below.

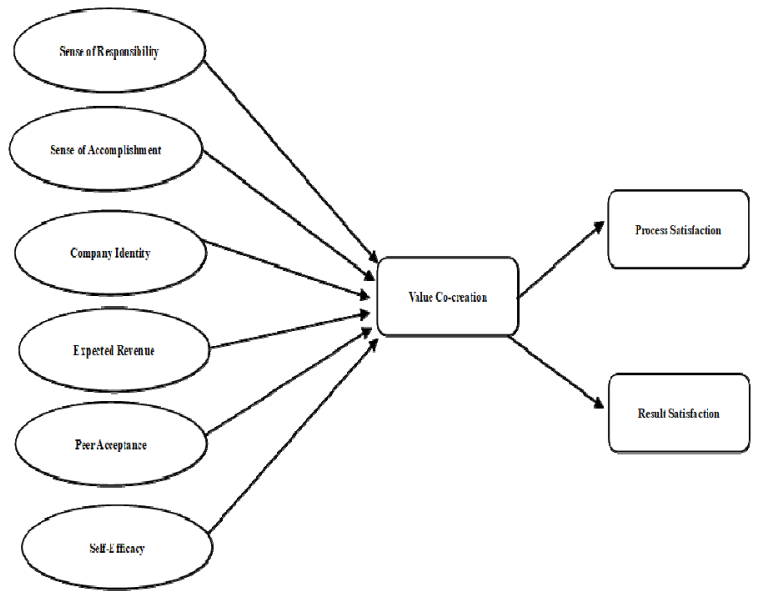

Figure 1. Conceptual Model.

\section{Empirical Analysis}

\subsection{Sample Information}

The survey respondents were shared bicycle users who meet the age requirements and once participated in value-creation activities. The questionnaire was issued for a total of two months, 452 were returned, and included 404 valid questionnaires. The effective recovery rate of the questionnaire was $89.4 \%$. Sample distribution is as follows. 
Table 1. Sample Information

\begin{tabular}{|c|c|c|c|}
\hline Fitle & Choice & Number of Cases & Percentage \\
\hline \multirow[t]{2}{*}{ Gender } & Male & 197. & $48.8 \%$ \\
\hline & Female & 207. & $51.2 \%$ \\
\hline \multirow[t]{5}{*}{ Age } & $18-25$ & 147. & $36.4 \%$ \\
\hline & $26-35$ & 185 & $45.8 \%$ \\
\hline & $36-45$ & 60. & $14.9 \%$ \\
\hline & $46-55$ & 9 & $2.2 \%$ \\
\hline & 55 以上 & 3. & $0.7 \%$ \\
\hline \multirow[t]{4}{*}{ Education Background } & Junior College and below it. & .32。 & $8.0 \%$ \\
\hline & Junior College. & 49. & $12.1 \%$ \\
\hline & Undergraduate & 173 & $42.8 \%$ \\
\hline & Master and above it & 150 & $37.1 \%$ \\
\hline \multirow[t]{5}{*}{ Length of using shared bicycles. } & Under 3 months. & 30. & $7.4 \%$ \\
\hline & 3-6 months. & 103 & $25.5 \%$ \\
\hline & 6-12 months & 144. & $35.6 \%$ \\
\hline & 1.2 year & 101. & $25.0 \%$ \\
\hline & Above 2 years. & 26. & $6.5 \%$ \\
\hline \multirow{2}{*}{\multicolumn{2}{|c|}{$\begin{array}{l}\text { Which bicycle brand will you choose to Mobike } \\
\text { report the damaged bikes when you useofo }\end{array}$}} & 340 & $84.2 \%$ \\
\hline & & 215 & $53.2 \%$ \\
\hline \multirow[t]{3}{*}{ shared bicycles . } & Hellobike & 287. & $71.0 \%$ \\
\hline & Xongan Xing & 128 & $31.7 \%$ \\
\hline & Xiangqi & 142 & $35.1 \%$ \\
\hline
\end{tabular}

\subsection{Measuring Variables}

This questionnaire measures 9 variables. All variables are measured using the Likert 5 scale. 1 means very inconsistent and 5 means very consistent. Responsibility is based on Constant (1996), which consists of four items. ${ }^{12}$ The pursuit of accomplishment is based on Liu Liu's scale, which consists of four items. The company's recognition is based on the Wilson (2008) scale, which contains four items. ${ }^{13}$ The expected revenue is based on a study by Bhattacherjee (2001) and consists of four items. ${ }^{14}$ The design of peer recognition scale is based on the Wasko (2000) scale, which consists of three items. ${ }^{15}$ The scale used for self-efficacy is Bandura 1982 and consists of four items. The scale for value creation is $\mathrm{Li}$ Zhaohui, which consists of five scales. The process satisfaction is based on Andaleeb's scale. ${ }^{16}$ The result satisfaction is based on Suh's scale, which contains 4 items. ${ }^{17}$

\subsection{Reliability and Validity analysis}

This study first uses SPSS 24 for reliability and validity analysis. The alpha coefficient is generally used to measure the reliability of the questionnaire. The larger the alpha coefficient, the higher the reliability of the questionnaire. The results show that Cronbach's devaluation and combination reliability exceed the acceptable level of 0.7 . The KMO value is 0.883 , which is greater than 0.7 , indicating that the questionnaire is suitable for factor analysis. The item factor load in each dimension exceeds 0.5 , indicating that each variable has good convergence validity.

Table 2. Confirmatory Factor Analysis: Variables and

\begin{tabular}{|l|l|l|l|}
\hline Variable & $\alpha$ & CR & AVE \\
\hline $\begin{array}{l}\text { Sense of } \\
\text { Responsibility }\end{array}$ & 0.815 & 0.819 & 0.532 \\
\hline $\begin{array}{l}\text { Sense of } \\
\text { Accomplishment }\end{array}$ & 0.847 & 0.851 & 0.590 \\
\hline $\begin{array}{l}\text { Company } \\
\text { Identity }\end{array}$ & 0.819 & 0.822 & 0.538 \\
\hline Expected & 0.834 & 0.836 & 0.560 \\
\hline
\end{tabular}

\begin{tabular}{|l|l|l|l|}
\hline Revenue & & & \\
\hline Peer Acceptance & 0.803 & 0.804 & 0.579 \\
\hline Self-Efficacy & 0.840 & 0.844 & 0.577 \\
\hline $\begin{array}{l}\text { Value Co- } \\
\text { creation }\end{array}$ & 0.876 & 0.877 & 0.589 \\
\hline $\begin{array}{l}\text { Process } \\
\text { Satisfaction }\end{array}$ & 0.839 & 0.839 & 0.567 \\
\hline $\begin{array}{l}\text { Result } \\
\text { Satisfaction }\end{array}$ & 0.856 & 0.863 & 0.612 \\
\hline
\end{tabular}

\subsection{Analysis of fitness}

The study selected the hypothesis proposed by the AMOS 23 test. The fitting test results of the initial model show that most of the following commonly used fitting indicators are up to standard, but there are still two not meeting the standards.

\begin{tabular}{l|l|l|l|l|l|l|l|l}
\multicolumn{7}{c}{ Table 3. Initial model fitting test } \\
Fit Index & CFI & NFI & GFI & AGFI & PNFI & $\chi 2 /$ df & RMSEA & SRMR \\
\hline $\begin{array}{l}\text { Test } \\
\text { Vaule }\end{array}$ & 0.974 & 0.896 & 0.910 & 0.896 & 0.812 & 1.303 & 0.027 & 0.043 \\
\hline $\begin{array}{l}\text { Reference } \\
\text { Value }\end{array}$ & $>0.90$ & $>0.90$ & $>0.90$ & $>0.90$ & $>0.50$ & $<2.00$ & $<0.08$ & $<0.05$ \\
\hline
\end{tabular}

From the above results, it can be seen that the indicators AGFI, NFI are close to 0.9, and all the remaining values reach the ideal value. In general, the model is acceptable, but the model can be modified appropriately.

Table 4. Residual Correction Index Table

\begin{tabular}{|c|c|c|c|c|} 
& & & M.I. & Par Change \\
\hline $\mathrm{e} 29$ & $<->$ & $\mathrm{e} 31$ & 23.883 & .147 \\
\hline $\mathrm{e} 25$ & $<->$ & $\mathrm{e} 27$ & 23.205 & .132 \\
\hline $\mathrm{e} 14$ & $\longleftrightarrow-\infty$ & $\mathrm{e} 15$ & 8.921 & .092 \\
\hline
\end{tabular}

It can be seen from the above table that the correction relationship between the newly corrected e29 <-->e31, e25<-->e27, e14<-->e15 is positive, and it is also in line with the actual situation, indicating that the correction is valid. The corrected structural equation is shown in the figure below. 


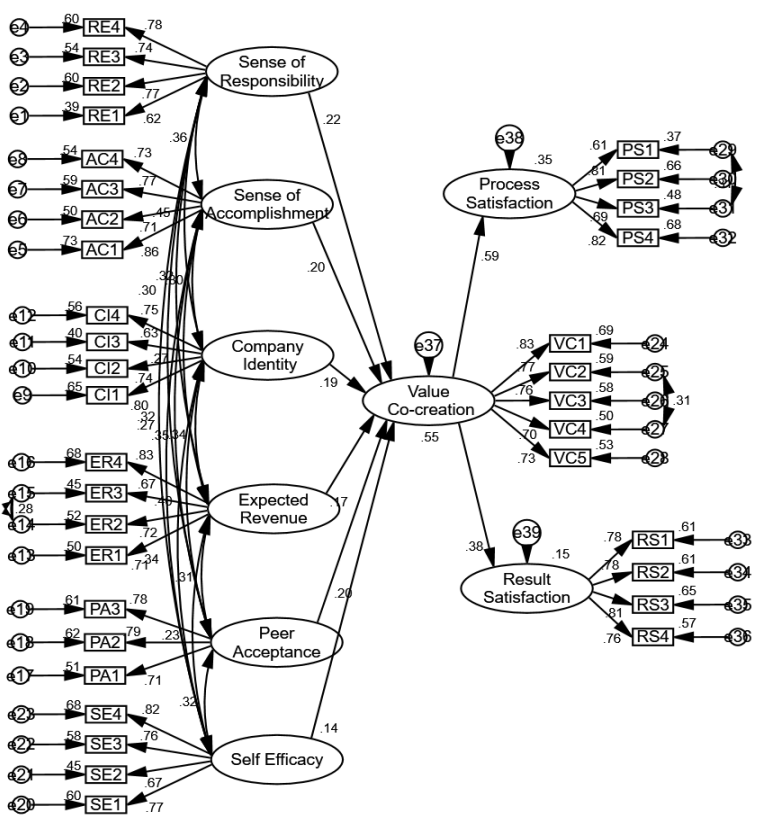

Figure 2. Structural Equation Diagram

Table 5. Modified model fitting test

\begin{tabular}{|l|l|l|l|l|l|l|l|l} 
Fit Index & CFI & NFI & GFI & AGFI & PNFI & $\chi 2 /$ df & RMSEA & SRMR \\
\hline $\begin{array}{l}\text { Test } \\
\text { Vaule }\end{array}$ & 0.984 & 0.906 & 0.919 & 0.905 & 0.817 & 1.180 & 0.021 & 0.041 \\
\hline $\begin{array}{l}\text { Reference } \\
\text { Value }\end{array}$ & $>0.90$ & $>0.90$ & $>0.90$ & $>0.90$ & $>0.50$ & $<2.00$ & $<0.08$ & $<0.05$ \\
\hline
\end{tabular}

\subsection{Analysis of fitness}

The hypothesis test results of the structural relationship between the variables in this study are as follows. It is generally considered that the estimated value of the parameter statistic reaches a significant level at $\mathrm{P}<0.05$. The results show that sense of responsibility, pursuit of accomplishment, company identity, expected revenue, peer acceptance, self-efficacy have positively promoted the value-creation behaviour of shared bicycle users, and the value creation behaviour of users has positive impact on the process satisfaction and results satisfaction.
Table 6. Hypothesis test results

\begin{tabular}{|c|c|c|c|}
\hline Hypothesis Testing Roadmap & $\begin{array}{l}\text { Standardized } \\
\text { path coefficients }\end{array}$ & Value $P$ & Conclusion \\
\hline $\begin{array}{c}\text { Hypothesis } 1 \text { : Sense of Responsibility } \\
\longrightarrow \text { Value Co-Creation }\end{array}$ & .221 & $* * *$ & Support \\
\hline $\begin{array}{l}\text { Hypothesis2: Sense } \\
\text { Accomplishment } \\
\text { Value Co-Creation }\end{array}$ & . 197 & $* * *$ & Support \\
\hline $\begin{array}{l}\text { Hypothesis3 : Company Identity } \\
\longrightarrow \text { Value Co-Creation }\end{array}$ & .188 & .001 & Support \\
\hline $\begin{array}{c}\text { Hypothesis4 : Expected Revenue } \\
\longrightarrow \text { Value Co-Creation }\end{array}$ & .171 & $* * *$ & Support \\
\hline $\begin{array}{l}\text { Hypothesis 5: Peer Acceptance } \\
\longrightarrow \text { Value Co-Creation }\end{array}$ & . 197 & $* * *$ & Support \\
\hline $\begin{array}{l}\text { Hypothesis6: Self-efficacy } \\
\longrightarrow \text { Value Co-Creation }\end{array}$ & .136 & .008 & Support \\
\hline $\begin{array}{l}\text { Hypothesis7: Value Co-Creation } \\
\longrightarrow \text { Process Satisfaction }\end{array}$ & .589 & $* * *$ & Support \\
\hline $\begin{array}{l}\text { Hypothesis8 : Value Co-Creation } \\
\longrightarrow \text { Result Satisfaction }\end{array}$ & .385 & $* * *$ & Support \\
\hline
\end{tabular}

\section{Conclusion}

The research results show that the sense of responsibility, the pursuit of accomplishment, company identity, expected revenue, peer acceptance, self-efficacy play a positive role in the value-creation activities shared bicycle users participate, and the value-creation behaviour of users also have a positive impact on process satisfaction and results satisfaction. The enlightenment for the development of shared bicycle companies is that, first of all, in the aspect of enterprise recognition, many shared bicycle brands are not well known to consumers, so consumers are not strong in brand recognition, and the enthusiasm for participating in value creation activities will also decline. Therefore, in the future development plan of the shared bicycle company, the company should strengthen the consumer's sense of corporate recognition and enhance their awareness of the bicycle brand through market activities and participation of the consumer. The sense of recognition is enhanced and the willingness of users participating in value-creation activities will increase.

In terms of peer acceptance, consumers will be more motivated to participate in co-creation activities when they are recognized by others. However, the existing shared bicycle value creation system does not have a credit score comparison mechanism with others, which inhibits the enthusiasm of consumers to participate in cocreation activities to a certain extent. Therefore, in the improvement of the future co-creation system, the shared bicycle company should introduce a credit rating system, so that users can get recognition from others in the credit rating, and generate a sense of accomplishment in the heart, and further stimulate their value co-creation activities after meeting the expected expectations. 
In terms of self-efficacy, the existing shared bicycle reporting system is not perfect. Many new users are not sure how to report damaged vehicles, and what benefits can be brought to them by reporting, so this reduces the possibility of their participation in the process. Therefore, when sharing bicycle companies encourage users to participate in value creation activities, they should first optimize the entire process of user participation, so that users can easily improve the experience.

The user's result satisfaction is not as obvious as the process satisfaction. The main reason is that the system lacks the feedback link of the corresponding user behaviour, that is, the user cannot get rewards like points, economic revenues after giving the company their own advice. This has reduced the enthusiasm of users. Therefore, the shared bicycle company should give positive feedback to the behaviour after the user participates in the value creation activity, which can further stimulate the user's willingness to participate.

\section{Shortage of the Research and prospects}

This study has some new findings on the motivational factors affecting value co-creation behaviour and explores the value co-creation behaviour' impact on the results, but there are still some shortcomings.

First of all, although the questionnaire asks about the length of use of shared bicycles, the length of use is not considered as a factor in the specific analysis. Therefore, in the future research, the time series should be added as a control variable to explore whether different durations of use will have different effects on the value-creation behaviour of shared bicycle users.

Secondly, because shared bicycle companies have more deliveries in large cities than small cities, the respondents to the questionnaire are concentrated in large cities, and regional factors may lead to different research results. Therefore, in the future, after sharing bicycles are distributed in more small cities, more indepth exploration is needed.

\section{References}

1. P. Demaio,. J. Public .Trans, 12,4（2009）

2. C.K. Prahalad, V. Ramaswamy, J. Interact. Mark ,3,5(2004)

3. W.D. Hoyer, R. Chandy, R., M. Dorotic, M. Krafft, S.S. Singh, J. Ser. Res 13, 283(2010)

4. J. Fuller, Calif. Manage. Rev, 52,98(2010)

5. X.X.Wang, H. B. Xue, Com economy and mgt, 10,63(2008)

6. Y. J. Peng, China circulation economy, 8,70(2014)

7. A. Muniz, T. O'Guinn, J Consum. Res, 27,412(2001)

8. T.A. Swartz, D. lacobucci, Handbook of Services Marketing and Management (Sage Pubns, 2000)

9. M. Hogg, D. Abrams, Group Motivation: Social Psychological Perspectives (Prentice Hall, 1993)
10. B. Edvardsson, B. Tronvoll, T.Gruber, J. Acad. Market. Sci. 39,327(2011)

11. T. Avnet, E. T. Higgins, J. Marketing. Res, 9,24(2006)

12. D. Constant, S. Sproull, Organ. Sci. 7,119(1996)

13. T. D. Wilson, D.T. Gilbert, Perspect. Psychol. Sci,3,370( 2008)

14. A. Bhattacherjee A, MIS Quart, 25,351(2001)

15. M. Wasko, S. Faraj, J Strategic. Inf. Syst, 9, 155(2000)

16. S. Andaleeb, K. Basua, J. Retailing, 70,367(1995)

17. J. Suh, Y.J Yi, J. Consum. Psychol, 16,145(2006) 